\title{
Concepção da Gestão Social e da Cidadania Deliberativa na Avaliação do Controle Social do Conselho Municipal de Educação de Grajaú - MA
}

Conception of Social Management and Deliberative Citizenship in the Assessment of Social Control of the Municipal Council of Education of Grajaú - MA

Concepción de la Gestión Social y Ciudadanía Deliberativa en la Evaluación del Control Social del Consejo Municipal de Educación de Grajaú - MA

Recebido: 01/03/2021 | Revisado: 09/03/2021 | Aceito: 19/05/2021 | Publicado: 04/06/2021

\author{
Jorcelyo Alencar Lima \\ ORCID: https://orcid.org/0000-0002-5530-7937 \\ Universidade Federal do Tocantins, Brasil \\ E-mail: j.alencar2008@hotmail.com \\ Marisa de Sousa Brito \\ ORCID: https://orcid.org/0000-0002-0209-9898 \\ Universidade Federal do Tocantins, Brasil \\ E-mail: msbritoecon@gmail.com
}

\begin{abstract}
Resumo
Os Conselhos Municipais de Educação representam um instrumento importante na gestão social. Nesse contexto, o presente trabalho tem como objetivo avaliar a concepção da gestão social e da cidadania deliberativa na avaliação do controle social do Conselho Municipal de Educação do município de Grajaú-MA. Inicialmente foi realizada a pesquisa bibliográfica com base em autores que estudam a temática em questão. Houve a observação não participante das atividades do CME. Em seguida, foram aplicados questionários, cujos resultados foram demonstrados em gráficos do tipo radar, bem como a apresentação das entrevistas junto aos conselheiros titulares e suplentes dos diferentes segmentos que compõem o referido Conselho. Frente ao exposto, os resultados obtidos refletem uma participação ainda deficiente, o que compromete parcialmente a efetivação da cidadania deliberativa.
\end{abstract}

Palavras-chave: Conselho de educação; Gestão social; Cidadania deliberativa.

\begin{abstract}
Municipal Councils of Education represent an important instrument in social management. In this context, this paper aims to evaluate social management and deliberative citizenship in the evaluation of social control of the Municipal Education Council of the city of Grajaú-MA. Initially, a bibliographic search was performed based on authors who studied the theme in question. There was a non-participant observation of WEC activities. Subsequently, the questionnaires were selected, the results were shown in radar graphs, as well as a presentation of the interviews alongside the full members and alternate members of the different filters that make up the consulted council. Given the exposure, the results achieved reflect a still poor participation, or compromise the effectiveness of deliberative citizenship.
\end{abstract}

Keywords: Education council; Social management; Deliberative citizenship.

\section{Resumen}

Los Consejos Municipales de Educación representan un instrumento importante en la gestión social. En este contexto, el presente trabajo tiene como objetivo evaluar la concepción de la gestión social y la ciudadanía deliberativa en la evaluación del control social del Consejo Municipal de Educación del municipio de Grajaú-MA. Inicialmente, se llevó a cabo una investigación bibliográfica basada en autores que estudian el tema en cuestión. Hubo observación no participante de las actividades de la CME. Luego, se aplicaron cuestionarios, los resultados se demostraron en gráficos tipo radar, así como la presentación de entrevistas con los directores completos y suplentes de los diferentes segmentos que componen el consejo. En vista de lo anterior, los resultados obtenidos reflejan una participación todavía deficiente, que compromete parcialmente la realización de la ciudadanía deliberativa.

Palabras clave: Junta de educación; Gestión social; Ciudadanía deliberativa. 


\section{Introdução}

A educação sempre foi uma preocupação da humanidade. Pensar em educação é pensar em uma cultura que consiga preservar seus costumes e assegurar sua integridade social, mental, emocional e psicológica. A saúde emocional e o bem-estar do homem encontram-se intimamente ligados à educação. A formação educativa pode advir tanto do ensino formal quanto do informal.

Nesse contexto, o Estado constitui-se em pessoa jurídica instituída pelos seres humanos com o principal objetivo de manter a ordem e a segurança, e, nesse contexto, o Estado exerce o que se pode denominar de jurisdição universal sobre o seu território no qual, ele, Estado, mantém a ordem através do Direito, cujo respaldo se dá pela delegação que lhe é conferida pelo povo que em seu território habita. Desta maneira, é o Estado quem produz, aplica e se sujeita ao Direito, mas que, no entanto, não é o Direito, ele é fruto deste.

O estudo desenvolve a temática sobre a ação dos Conselhos Gestores municipais como parte do processo de decisão das políticas públicas que vem a beneficiar a comunidade local, trazendo o papel da gestão social como norteadora das atividades desenvolvidas pela representatividade dos indivíduos sociais no segmento da educação no município de Grajaú, no estado do Maranhão.

Os debates oriundos do diálogo sociedade-estado, com ênfase na participação cidadã passou a ter mais representatividade nos governos locais, visto que a democracia representativa por si não é suficiente para atender as demandas sociais (Tenório, 2012, p. 13).

As ações pontuadas por essa cogestão possibilitam a maior transparência do processo e propicia, se efetuada de forma efetiva, o controle social das políticas públicas, por ser um mecanismo de legitimação da participação e envolvimento dos cidadãos nas decisões significativas para a comunidade.

Os Conselhos Gestores são previstos na Constituição do Brasil (1988/2019), com especial atenção nos seus artigos 198, 204 e 206, como mecanismos institucionalizados de controle social. O papel dos conselhos setoriais de representação e participação são importantes estruturas de aproximação da sociedade com complexidades das questões públicas, devendo ser ampliado e diversificado para melhor gestão de problemas que impactam em todo o âmbito social, além da partilha de poder conjunta para resolução destes.

Diante do cenário político atual, a participação de cada gestor público deve ser clara, tendo em vista que foram escolhidos como representantes do povo para suprir uma necessidade de organização coletiva, visando o bem comum. Em tese significa uma forma que os indivíduos sociais encontraram de se organizar para viver em coletividade, colocando nas mãos de alguns a autoridade, a responsabilidade e o dever de administrar o ambiente comum.

O presente trabalho foi desenvolvido com o objetivo de analisar a concepção da gestão social e da cidadania deliberativa na avaliação do controle social do Conselho Municipal de Educação de Grajaú-MA. A escolha do tema se deu em decorrência da necessidade dos cidadãos em participar do controle social através dos conselhos, constituídos como espaços de gestão social.

A metodologia utilizada na construção da pesquisa foi inicialmente de cunho bibliográfica. Houve a observação não participante dos autores no ambiente de trabalho do CME durante um ano. Durante esse período foi realizada uma pesquisa de campo junto aos representantes do Conselho Municipal de Educação de Grajaú-MA, tendo sido entrevistados representantes dos diversos segmentos que o compõe.

No conselho municipal de educação da cidade de Grajaú - MA buscou-se identificar se este versa como exemplo de ação deliberativa com participação de membros da sociedade na tomada de decisão, no exercício da cidadania efetiva. Para esse processo foi efetuado o Caderno de Campo, visitas ao espaço do CME, solicitação de documentos, participação das reuniões oficiais e extraoficiais, aplicação de questionário, que são os instrumentos base para a confecção deste trabalho. 


\section{Conceituando a Gestão Social}

O Estado Democrático de Direito significa que há a participação popular nas decisões administrativas da coisa pública, haja vista que o cidadão comum persegue a evolução e faz valer o seu direito soberano de conduzir, embora externamente, o destino do que seria a aplicação do dinheiro público em prol do próprio cidadão.

É sob essa concepção de liberdade de atuação que o povo deve exercer o seu poder sobre o Estado, dando-lhe a permissão para a gerência dos seus interesses gerais, diante da sua dimensão. Porém buscando conduzir o que seja melhor à sua realidade local, participando de forma a diminuir as barreiras entre Estado e sociedade. Assim, de certa forma, diminui o poder do Estado e o "força" a trabalhar em prol das reais necessidades dos cidadãos.

A concepção do conceito de Gestão Social tem início no final dos anos 80, encontrando nos seus elementos estruturantes a percepção de que a participação e controle social devem ser efetuados a partir da cidadania deliberativa, se contrapondo as formas de gestão estratégica empregadas pela dinâmica neoliberal difundida nesse período.

Nunes (2018) relata que no Brasil, após a Carta Magna de 88, algumas ações políticas têm sido executadas no intuito de estimular a sociedade na fiscalização das atividades estatais de maneira a buscar um novo modelo de relação entre o Estado e o cidadão pautado na transparência, garantia de direitos e na qualidade do acesso aos serviços públicos, dentro os quais merecem destaque os conselhos gestores de políticas públicas.

Para o caso brasileiro a temática passou a ser incorporada através do debate acadêmico para as políticas públicas a partir dos anos 90. Segundo França (2008, p. 27):

[...] a expressão gestão social tem sido usada de modo corrente nos últimos anos servindo para identificar as mais variadas práticas sociais de diferentes atores não apenas governamentais, mas sobretudo de organizações nãogovernamentais, associações, fundações, assim como, mais recentemente, algumas iniciativas partindo mesmo do setor privado e que se exprimem nas noções de cidadania corporativa ou de responsabilidade social da empresa.

O autor salienta que se trata de um conceito complexo explicar a gestão social e suas vertentes, mas "efetivamente, enquanto problemática de sociedade, a ideia de gestão social diz respeito à gestão das demandas e necessidades do social" (França, 2008, p. 29).

É possível pontuar, com base em França (2008,) que o formato de organizar e tomar decisões dessa área de conhecimento pode corresponder então "ao modo de gestão próprio às organizações atuando num circuito que não é originariamente aquele do mercado e do Estado", visto que a sociedade tem um espaço para participação efetiva.

A polissemia conceitual da Gestão Social é percebida como campo em construção, a qual pode ser remetida como gestão democrática e participativa, visto que permite o diálogo dos diversos segmentos da sociedade organizada, com intuito de compartilhar, com todos os envolvidos na ação, a autoridade decisória (Tenório, 2016).

Como campo em construção Cançado (2013) explana que "a gestão social é um campo de conhecimento com fundamentos teóricos específicos”, com categorias e critérios teóricos de demarcação próprios. Pontua ainda que se trata da “. . .tomada de decisão coletiva, sem coerção, baseada na inteligibilidade da linguagem, na dialogicidade e entendimento esclarecido como processo, na transparência como pressuposto e na emancipação enquanto fim último" (Cançado, 2011, p. 99).

Para a relação partilhadas entre o Estado e a sociedade os autores Comerlatto, Matiello, Colliselli, Renk e Kleba (2007, p. 266) comentam que:

A gestão social exige que o conjunto das políticas públicas e as instituições que as programam redimensionem o processo de formular e operacionalizar suas estratégias e ações. Além disso, a instauração de modelos flexíveis e participativos que envolvam negociação e participação dos usuários e demais interlocutores nas decisões e ações das diversas políticas públicas 
Acrescentando a essa discussão, Tenório $(2009$, p. 2) inda pontua que a Gestão Social se trata de: “. . . uma gestão ampliada na qual o processo decisório seria vinculante ao diálogo consciente, procedimental, por meios dos diferentes atores da sociedade, sob a perspectiva de sujeitos em ação".

Para Nunes (2018), a gestão social busca pelo atendimento à gestão de demandas e necessidades sociais. Corroborando em ideia semelhante, Silveira, Cançado e Pinheiro (2014) inferem que atualmente a gestão social conduz ao foco no social.

\section{Cidadania Deliberativa na Avaliação do Controle Social}

Sob a ótica de Nunes (2018), o Estado e a sociedade civil, ao longo dos anos, tem interagido de forma a reconhecer novos atores sociais de maneira que alguns segmentos têm sido incorporados ao sistema político, que antes eram mantidos à margem do sistema de maneira que observasse um modelo de organização social e política mais democrático e participativo.

Para Allenbrandt e Tenório (2018) a possibilidade decisória da cidadania deliberativa considera os conceitos de esfera pública e sociedade civil, essenciais para a sua compreensão. A esfera pública é o espaço da discussão e do diálogo e a sociedade civil é a formação de diversos segmentos com representatividade para apoiar as tomadas de decisão sobre as diversas necessidades do social.

Silveira, et al. (2014) relatam que a sociedade tem se engajado nas demandas de ordem coletiva ao longo dos anos. No entanto, a cidadania participativa requer tempo, conhecimento e vontade do cidadão.

Nesse sentido Iizuka, Gonçalves-Dias e Aguerre (2011) informam que os processos que tratam de desenvolvimento local vão implicar ações organizadas feitas pelos atores estatais, da sociedade civil e do capital, mas que todos os envolvidos devem estar preparados para seguir com projetos que surgirão da "negociação de interesses, inclusive divergentes e em conflito".

Em se tratando do segmento da educação e a democratização do ensino, é importante identificar que os primeiros sujeitos do processo são os professores, que nesse âmbito devem ter uma formação e valorização profissional, incluindo melhoria das condições de trabalho. Tal processo envolve diversos aspectos fundamentais: desde a formação inicial e continuada, articulada, identitária e profissional. Essa formação identitária é epistemológica, ou seja, reconhece a docência como um campo de conhecimentos específicos configurados em quatro grandes conjuntos.

Observando a existência desses conjuntos é possível determinar suas configurações: O primeiro conjunto configura-se nos conteúdos relativos a diversas áreas do saber e do ensino, ou seja, das ciências humanas e naturais, da cultura e das artes. Já o segundo, trata dos conteúdos didático-pedagógicos, diretamente relacionados ao campo da prática profissional. No terceiro conjunto, estão os conteúdos ligados a saberes pedagógicos mais amplos do campo teórico da prática educacional, enquanto o quarto e último campo relacionam os conteúdos ligados à explicitação do sentido da existência humana individual, com sensibilidade pessoal e social (Oliveira \& Adrião, 2007).

Ser professor requer saberes e conhecimentos científicos, pedagógicos, educacionais, sensibilidade, indagação teórica e criatividade para encarar as situações ambíguas, incertas, conflituosas e, por vezes, violentas, presentes nos contextos escolares e não escolares. É de natureza docente proceder à mediação reflexiva e crítica entre as transformações sociais concretas e a formação humana dos alunos, questionando os modos de pensar, sentir, agir e de produzir e distribuir conhecimentos (Oliveira \& Adrião, 2007, p. 14).

O Ministério da Educação e Cultura (MEC) vem mobilizando os sistemas de ensino e as instituições formadoras no intuito de oferecer condições para que o profissional se desenvolva e seja valorizado através de cursos de habilitação e formação continuada, levando em conta sua realidade e a revisão dos planos de cargos e salários. 
Vale destacar que para Fuks, Perissinotto e Suoza (2004), existe a tendência das organizações a canalizar suas demandas para atores estratégicos que fazem parte de sua rede de apoio político ou para os espaços institucionais mais permeáveis às suas demandas.

Na busca pelo entendimento mútuo, Allenbrandt e Tenório (2018) entendem que cabe à esfera pública a identificação, compreensão, problematização e ainda propor soluções aos problemas da sociedade (um município, um bairro, uma comunidade, etc.), de forma a que essas soluções contribuam para o desenvolvimento ou controle de políticas públicas.

Assim Nunes (2018, pp. 15-16) pontua que:

Os conselhos gestores de políticas são espaços de co-gestão entre Estado e sociedade que contrapõem a tradição imperiosa e excludente que caracteriza os espaços de decisão política no Brasil onde muitas vezes prevalecem práticas patrimonialistas e clientelistas. São formas inovadoras de gestão que permitem a incorporação das forças vivas de uma comunidade na identificação, solução e controle de seus problemas sociais.

O desenvolvimento profissional dos professores é objetivo de propostas educacionais valorizadoras, não mais da formação com base na racionalidade técnica, como meros executores das disposições alheias, porém com uma perspectiva reconhecedora da sua capacidade de decisão.

Assim torna possível a transformação do segmento baseado nas reais necessidades dos seus participantes, visto que esses são elementos de ação ativa nas demandas, problematização e busca por resolução destas.

\section{O Conselho Municipal de Educação de Grajaú - MA}

O Conselho Municipal de Educação de Grajaú foi criado pela Lei n. 006 (2005) para "estimular e propor a formulação de políticas para a educação municipal, que vem dispor em seu parágrafo único como "de caráter deliberativo, normativo, fiscalizador e controlador da destinação e aplicação dos recursos para a educação".

No acompanhamento anual foi analisado se há a aplicação de critérios da gestão social e participação ativa da sociedade através da sua representatividade, que para a devida observação desse processo foi necessário a participação passiva dos autores, onde houve a realização de visitas agendadas e acompanhamento das reuniões do conselho.

O CME de Grajaú é composto por representação, conforme o $4^{\circ}$ artigo da lei de criação deste, de acordo com o esquema abaixo (Lei n. 006, 2005):
a) Um representante da Secretaria Municipal de Educação;
b) Um representante do Sindicato dos Trabalhadores Municipais;
c) Um representante das Associações das entidades comunitárias organizadas;
d) Um representante da Associação de Pais de Alunos;
e) Um representante da Câmara dos Vereadores, indicados pelo plenário;
f) Um representante dos alunos;
g) Um representante da Secretaria de Estado da Educação.;
h) Um representante do poder executivo;
i) Um representante das escolas particulares;
j) Um representante das universidades existentes no município.

A partir da Emenda n. 002 (2016) houve a integração de mais representantes da sociedade para o CME de Grajaú/MA, a citar: a) Um representante indígena; b) Um representante quilombola. Com a alteração expandiu-se a abertura de diálogo com mais segmentos da sociedade, para repartição de responsabilidades no processo de tomada de decisão do município, no âmbito da educação. 


\section{Concepção da Gestão Social e da Cidadania Deliberativa na Avaliação do Controle Social do Conselho Municipal de Educação de Grajaú - MA}

\subsection{Trilhar metodológico}

Por meio dos procedimentos metodológicos em uma produção acadêmica é possível identificar o processo que será desenvolvido na realização do trabalho, pois a metodologia tem como objetivo definir as etapas e meios para a execução das atividades em questão, "a metodologia é a explicação minuciosa, detalhada, rigorosa e exata de toda ação desenvolvida no método (caminho) do trabalho de pesquisa" (Bello, 2008, p. 20). Assim é possível traçar a estrutura para análise da realidade das tomadas de decisões alicerçadas pelo papel dos Conselhos Gestores, que impactam as ações públicas.

A princípio foi realizada a pesquisa bibliográfica (livros, artigos, teses, leis) que nos forneceu base teórica para debater a Gestão Social, cidadania deliberativa, os conselhos gestores, sendo a parte introdutória deste trabalho (Gil, 2010).

Ainda serão detalhados os instrumentos utilizados para construção da pesquisa, pois trata-se da etapa onde serão definidos os caminhos para a realização da pesquisa, seus aspectos e os meios utilizados deste os elementos iniciais, chegando até os resultados alcançados.

A presente pesquisa utilizou análise quantitativa e qualitativa por meio de entrevistas semiestruturadas junto aos conselheiros titulares e suplentes, bem como observação direta não participante nas reuniões do Conselho de Educação de Grajaú.

No processo in loco efetuou-se a utilização de Caderno de Campo (ferramenta de anotação manual dos eventos), para o acompanhamento não-participante das atividades desenvolvidas pelo CME de Grajaú-MA, a qual a cada contato com o objeto de estudo foi registrado as impressões com a visão do pesquisador.

A aplicação do questionário estruturado foi necessária para vislumbrar a participação dos conselheiros nos processos de tomada de decisão de pautas relacionadas aos trabalhos do CME. Constituíram a pesquisa de campo a aplicação de 19 (dezenove) questionários e as entrevistas de 6 (seis) conselheiros titulares e suplentes dos diferentes segmentos que compõem o referido Conselho, essas ações foram realizadas no mês de outubro de 2019.

\subsection{Resultados e discussões}

O Conselho Municipal de Educação de Grajaú tem em média 14 anos de funcionamento. É composto por 1 representante da SEMED; 1 representante dos trabalhadores municipais; 1 representante das entidades comunitárias; 1 representante da associação de pais de alunos; 1 representante da Câmara dos Vereadores, indicado pelo plenário; 1 representante dos alunos; 1 representante da Secretaria Estadual de Educação; 1 representante do Poder Executivo; 1 representante das escolas particulares; 1 representante das Universidades existentes no município. Todos com um titular e um suplente.

Inicialmente os questionários foram aplicados seguindo a dinâmica de divisão em blocos. O primeiro bloco trata sobre os dados demográficos, conforme demonstrado no Gráfico 1. 
Figura 1. Categorias da Cidadania Deliberativa.

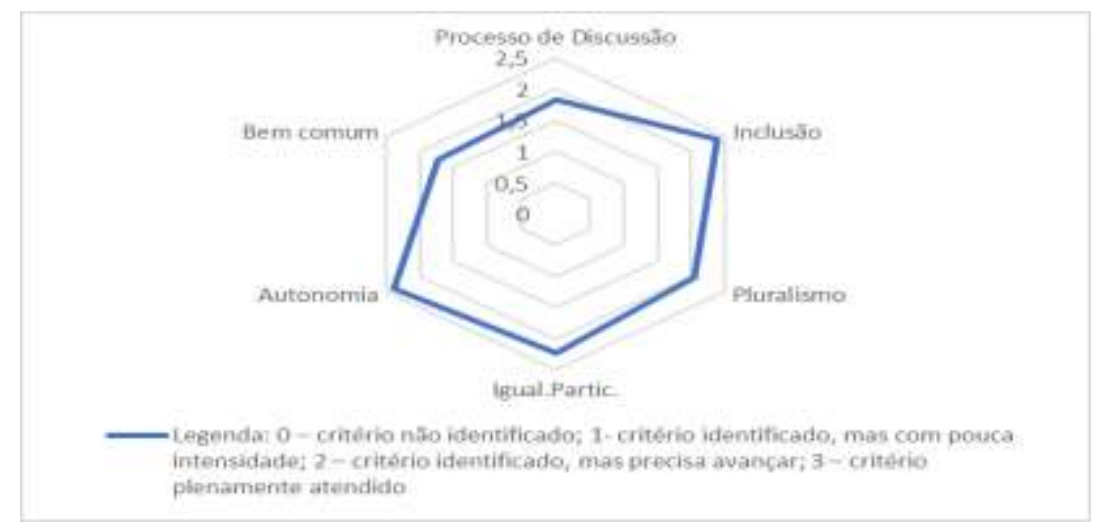

Fonte: Elaboração realizada a partir dos dados obtidos em pesquisa.

No tocante ao primeiro gráfico, foram analisadas as categoriais da cidadania deliberativa, a qual inicialmente tem-se a categoria Processo de Discussão trazendo como ponto de análise a forma como funciona o debate e a tomada de decisão na esfera pública, por meio de um diálogo aberto entre os agentes. Na referida categoria são elencados os seguintes critérios: Canais de Difusão; Qualidade de Informação; Espaços de Transversalidade; Pluralidade do Grupo Promotor; Órgãos Existentes; Órgãos de Acompanhamento; e Relação com Outros Processos Participativos.

Os canais de difusão das atividades internas, segundo os entrevistados, ainda são efetuados de forma bastante prejudicada, conforme relacionado nas entrevistas. Com o questionamento sobre se a população do município conhece o conselho, uma das entrevistadas respondeu que: "A população conhece o conselho. O meio de comunicação que a gente tem aqui é somente o site".

A população de Grajaú, e acredito que a maior parte dos 217 municípios do Estado do Maranhão, pouco interagem com os Conselhos. Digo isso porque sou vice coordenadora da UNCME (União dos Conselhos Municipais de Educação do Maranhão) e participo de rodas ampliadas de conversa com conselheiros não apenas de Grajaú, mas de todo o Estado do Maranhão, inclusive eu tenho participado de plenárias estaduais, regionais e já participei de várias oportunidades de encontros nacionais de educação. Posso afirmar que, lamentavelmente, a população não está estreitamente ligada ao Conselho. Apesar de haver representação dentro dos conselhos, não existe um vínculo direto, para além dos conselheiros. O conselheiro, se ele tiver representatividade, por si só. Ele representa, por exemplo, os pais, se ele tiver uma visão ampliada, se ele for um conselheiro consciente e tiver uma larga visão acerca do seu papel dentro do conselho, ele pode vir a interagir satisfatoriamente no que tange a defesa de seu segmento. Do contrário, não.

Quanto aos meios de comunicação, ela respondeu que:

Não existe nenhum meio de comunicação estreitamente ligado à sociedade civil em relação ao conselho. Quando, por oportunidade dos meus dois mandatos, enquanto presidente do Conselho Municipal de Educação, fui, por várias vezes, às rádios locais e em várias rodas ampliadas de educação levar a palavra à defesa e, sobretudo, a funcionalidade do Conselho. Eu entendia, naquela oportunidade, e continuo a entender que não existe conselho ilhado do controle social. E se não houver estreita participação da sociedade civil para conhecer e mobilizar um diálogo, o conselho perde a sua essência, porque o conselho é anti-plural, feito por um caráter coletivo e a visão de muitos pode ocasionar o fortalecimento do conselho.

Acrescentou, com ênfase, que:

O fato é que nós estamos ainda correndo atrás de um prejuízo muito grande no que tange a esses espaços colegiados quanto à autonomia do conselho e do conselheiro, enquanto sujeito atuando dentro desse organismo no âmbito do 
sistema local. Lamentavelmente, nós ainda temos um prejuízo muito grande no que tange à comunicação, à autonomia, à compreensão de qual a verdadeira atuação e o papel dos conselheiros.

No que diz respeito à qualidade da informação, os entrevistados acreditam que se dá ainda de forma parcial, conforme relatos destes. Uma das entrevistadas disse ainda que a escolha do presidente do referido Conselho se dá por meio da sociedade civil que marcam uma reunião para escolha e em seguida procedem a votação. Disse não recordar a quantidade de presidentes.

Questionada de que forma as reuniões são conduzidas, ela relatou que é encaminhada uma carta, há reunião mensal para discussão as ações que serão propostas. As pautas das reuniões são feitas por uma pessoa designada para a função logo após a tomada de decisões. Os conselheiros participam ativamente de todas as discussões.

Segundo outro entrevistado:

Hoje a gente pode dizer que o conselho tem um funcionamento muito bom, inclusive funciona aqui em frente à Câmara Municipal de Grajaú. Os grupos de trabalho, em nome da presidente do Conselho, sempre vêm fazendo contato com a gente através do aplicativo de mensagens o whatsapp, apresenta a pauta da reunião e ao final nós fazemos uma avaliação do nosso trabalho perante as reuniões.

As pautas são construídas por meio das dificuldades enfrentadas pelo município. As discussões do conselho são bem claras, não havendo desconhecimento dos termos técnicos.

Para ele, a população do município deixa um pouco a desejar no que diz respeito à participação efetiva, mas atribui aos conselheiros uma parcela de culpa na falta de divulgação sobre as ações.

No tocante aos espaços de transversalidade, a maior parte dos entrevistados concordam totalmente que os debates são fomentados e os diferentes pontos de vista são respeitados. Resultado semelhante ao encontrado quando questionados sobre a pluralidade do grupo promotor.

Quanto aos demais critérios, os entrevistados relatam que a relação com outros órgãos ainda se dá de forma insatisfatória.

Na visão de uma das entrevistadas, a população conhece o funcionamento do conselho de forma parcial. Pouquíssimas são as informações em redes sociais sobre as ações desempenhadas. Disse ainda que o CME participa de diversos movimentos com outros conselhos, porém que necessita de um envolvimento maior.

Na opinião desta, o conselho atinge os objetivos de maneira parcial. “A principal dificuldade está nas instâncias, porque não depende só do conselho. Essas decisões dependem de outros encaminhamentos. É um dos pontos que encontramos dificuldades".

Indagado ainda se o conselho dialoga com outros conselhos, foi informado por ela: "Sim, nós estamos em constante contato com o Conselho Estadual, com o Conselho Nacional, UNCME, UNDINE. Sempre que se tem dúvidas aqui, costumase entrar em contato, principalmente com o Conselho Estadual".

Outra entrevistada afirmou que:

O Conselho é, como eu falei anteriormente, um órgão plural e precisa manter vínculos com o Conselho Estadual e com o Conselho Nacional, mas se a composição do conselho não for devidamente orientada, fica apenas no âmbito local. E isso faz com que haja um perigo muito grande que é do conselho ficar restrito ao aspecto técnico. E um conselho deve ser um organismo cuidador e zelador das políticas educacionais à luz do sistema para o lugar, para $\mathrm{o}$ município, para o Estado e para o País. Sem o conselho estar relacionado à instâncias superiores, ele minimiza o poder de atuação porque se enfraquece. E o enfraquecimento do conselho termina contribuindo para que ele se volte apenas ao aspecto tecnicista e não ao aspecto social e político. 
A segunda categoria, denominada Inclusão, é constituída por meio de critérios com o intuito de identificar a participação do conjunto diversificado de atores, tendo como critérios: Abertura dos Espaços de Decisão; Aceitação Social, Política e Técnica; e Valorização Cidadã.

Em relação aos critérios supracitados, os entrevistados acreditam que a abertura dos espaços de decisão é parcialmente atendida, mas com bastante aceitação social, política e técnica, bem como uma valorização cidadã.

No que diz respeito à representação estão presentes de diversos segmentos, como Estado, Sociedade Civil, entre outros.

A representação entre Estado e Sociedade Civil, segundo a entrevistada:

Nós temos aí, vamos dizer, em todos os conselhos, nós temos uma prerrogativa que a sociedade civil entra, aqui no caso de Grajaú, por meio das associações. Nessa atual composição, nós temos a participação dos trabalhadores rurais. Entra também por meio das escolas universitárias. Entra por meio do sindicato dos trabalhadores e trabalhadoras em educação do município. Entra por meio da representação de pais e estudantes. Então, nós temos aí uma maioria de sociedade civil.

A representação da divisão entre Estado e Sociedade, segundo a Lei Municipal 006/05, já traz esta divisão. Segundo ela: “O art.4 diz que o CME será composto pelos membros descritos na lei. Então é feita essa divisão de acordo com a Lei. Aí nós temos tanto a representação do Estado e da sociedade civil”.

Perguntada sobre as discussões no conselho, a entrevistada disse que:

A maioria dos conselheiros ingressam como representantes da sociedade civil, sem ter vínculo direto com a educação. Logo, eles passam por dificuldades de compreensão e de que como se processa o cotidiano do conselho. Para tanto, o ideal é que hajam formações. Lamentavelmente, nós sabemos que as formações, por mais que sejam solicitadas, elas nunca acontecem amplamente como é o desejado. E o fato é que as reuniões ocorrem, existe uma previsão de reuniões dentro da lei que cria, dentro do regimento interno e dentro do próprio plano de ação institucional. Essas reuniões se dão ordinária e extraordinariamente. Dentro dessas reuniões são conversadas, dialogados processos de discussão acerca das pautas que estão como prerrogativas do dia, da oportunidade.

Quanto à elaboração, avaliação e acompanhamento das políticas públicas, a entrevistada relatou que:

Os conselheiros atuam, participam e estão disponíveis. Nós temos uma dificuldade muito grande no que tange à regência do conselho, o ordenamento do conselho por conta das pessoas não terem a visibilidade de qual é o seu real papel dentro do conselho, mas os conselheiros participam, ainda que limitadamente por não terem uma ampla compreensão acerca de seu papel, mas participam do plano de ação, das demandas internas, das reuniões ordinárias e extraordinárias. Nós temos até melhorado esse nível de participação, mas isso é uma coisa que sempre vai incidir naquela questão de mobilidade, quem está à frente do conselho, precisa ser antes um mobilizador, porque, do contrário, não vai conseguir a participação de todos os membros, pois estes não se colocam como sendo co-criadores do conselho.

O Pluralismo constitui a terceira categoria, cuja finalidade é investigar a variedade, os interesses e as formas de atuação dos diferentes atores para garantia de um espaço democrático de debate. Seus critérios são: Participação de Diferentes Atores; e Perfil dos Atores.

Esses critérios foram apontados com alto grau de concordância, conforme relatos dos entrevistados.

A quarta categoria, Igualdade Participativa, contém análises sobre a efetividade da abertura e transparência do espaço de deliberação. Critérios: Forma de Escolha dos Representes; Discurso dos Representantes; e Avaliação Participativa.

O presidente é escolhido, segundo informado pela entrevistada, em uma assembleia, onde são convocados todos os representantes titulares e suplentes. 
Sabemos que o direito ao voto é do titular. E é colocado em votação, ou melhor, é colocado para quem quiser se candidatar. Sendo feita a votação. Nessa última eleição só houve uma candidata. Foi colocado em votação, foi dito pelo advogado do município que estava lá conduzindo os trabalhos, juntamente com o secretário. Foi perguntado se todos estavam de acordo. Se sim, que permanecessem sentados e os que não estivessem de acordo que se levantasse, tendo sido eleita por unanimidade. De 2005 para cá, nós já tivemos 5 presidentes.

A mesma relatou que a escolha se deu por meio de critério de pessoas que já tinham uma função, não em decorrência da qualificação. Segundo ela: "A representação dos membros de conselho se dá por meio de representantes legais, escolhidos pela sociedade, com um representante para cada segmento: Estado e sociedade civil”.

Quanto à composição do órgão em debate, outra entrevistada revelou que:

Nós temos a composição das três câmaras: a de Educação Básica, a de legislação e normas e a de Jovens e Adultos, porém esse ano nós estamos com dificuldades para reunir os membros das referidas câmaras para que seja feito um estudo de acordo com o regimento, de acordo com o que a gente realmente precisa. A comissão de avaliação também está nesse mesmo patamar. Nós estamos com muitas dificuldades em relação à presença dos membros.

A quinta categoria, Autonomia, através de seus diferentes critérios, ilustra as formas de atuação dos agentes quanto à tomada de posição própria e o grau de empoderamento permitido pelo processo participativo. Critérios: Origem das Proposições; Alçada dos Atores; Perfil da Liderança e Possibilidade de Exercer a Própria Vontade.

A sexta categoria, Bem Comum, com seus dois critérios, investiga os resultados e a forma como se atingem os resultados coletivos. Os critérios são: Objetivos Alcançados e Aprovação Cidadã dos Resultados.

O gráfico a seguir traz as características da Gestão Social Identificada. 
Research, Society and Development, v. 10, n. 6, e41910613440, 2021

(CC BY 4.0) | ISSN 2525-3409 | DOI: http://dx.doi.org/10.33448/rsd-v10i6.13440

Figura 2. Característica da Gestão Social Identificada.

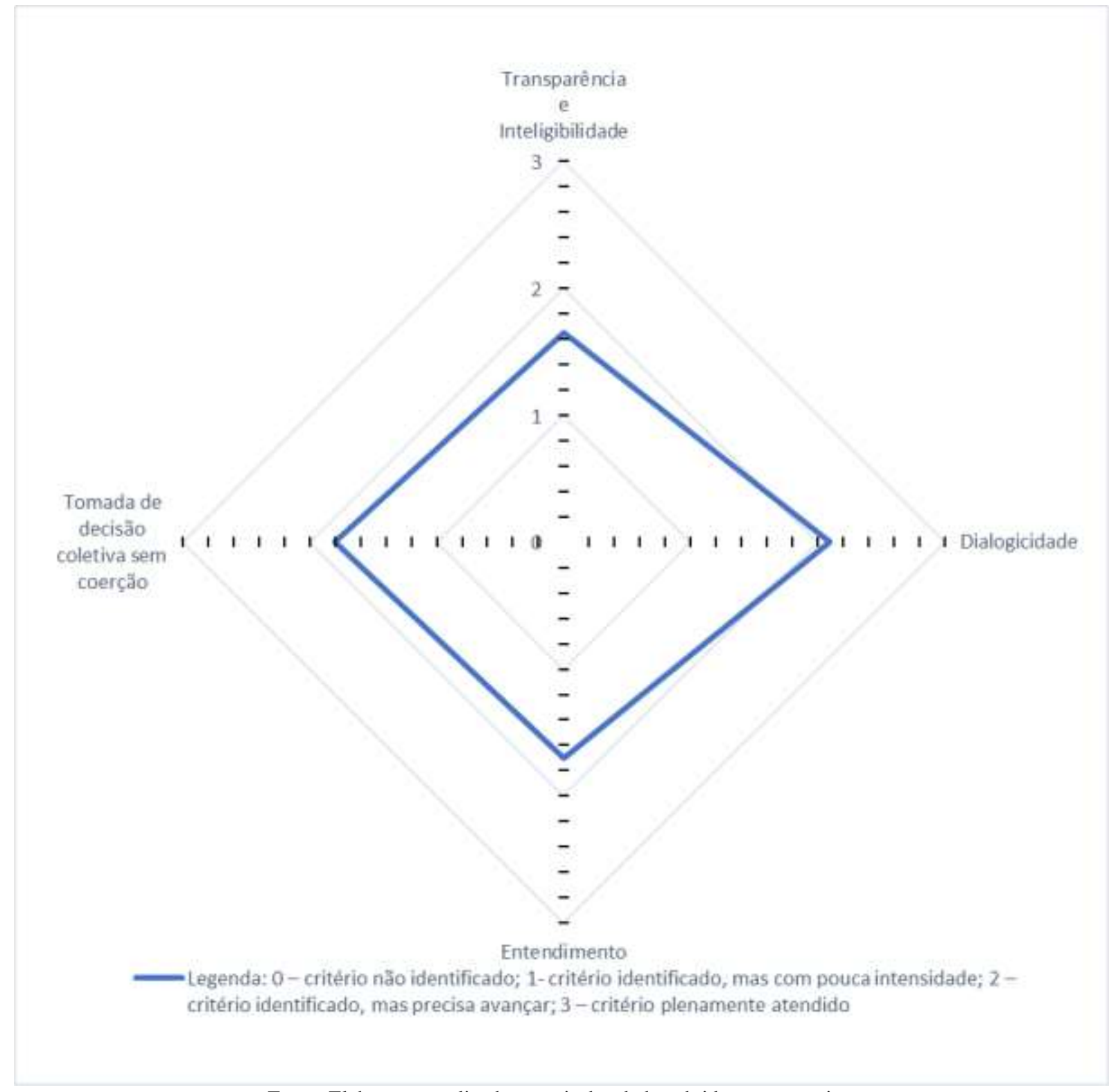

Fonte: Elaboração realizada a partir dos dados obtidos em pesquisa.

O gráfico 2 aponta que para melhorar a atuação do conselho, os entrevistados acreditam ser necessário um maior envolvimento da comunidade nas discussões quanto aos quesitos mais importantes. Os conselheiros participam ativamente na elaboração das políticas públicas. Relata que há empecilhos para atingimento dos objetivos.

No tocante às dificuldades, a falta de apoio da municipalidade foi apontada como um dos principais entraves, bem como a entrega de ofícios. Segundo ele, o conselho deveria ter mais autonomia para verificação e fiscalização de tudo aquilo que acontece na educação municipal. 
Figura 3. Síntese dos Critérios de Análise da Cidadania Deliberativa.

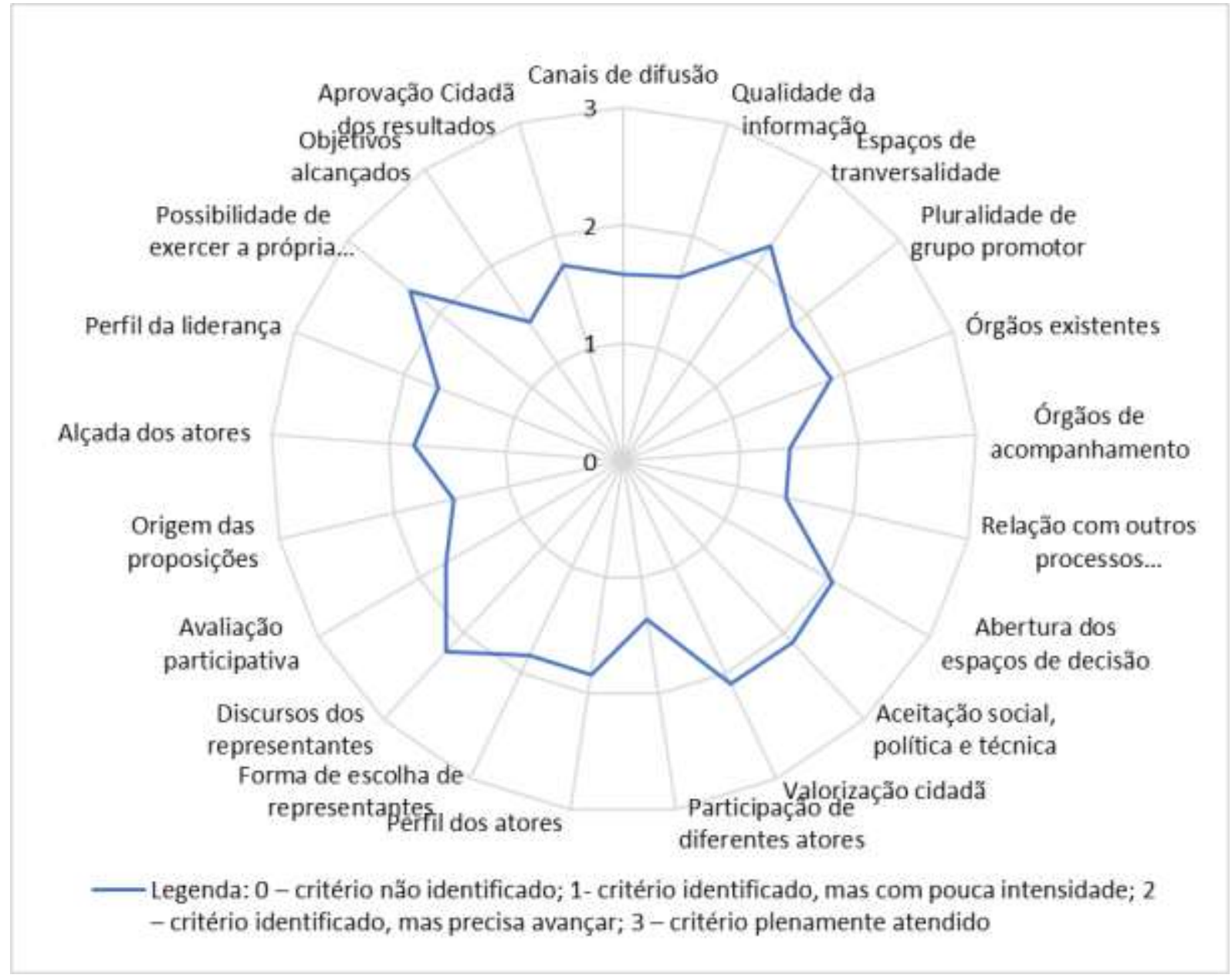

Fonte: Elaboração realizada a partir dos dados obtidos em pesquisa.

O Gráfico 3 traz uma síntese dos critérios de análise da cidadania deliberativa, a partir do qual é possível observar que, alguns atores precisam ter ciência de suas funções no contexto e participar de forma mais efetiva do trabalho desenvolvido pela Conselho Municipal de Educação de Grajaú-MA.

Os entrevistados relatam ainda que convivem com dificuldades de cunho financeiro, pois ainda há bastante limitação de recurso dessa natureza. No que pertine ao funcionamento do conselho, o Conselho Municipal de Educação de Grajaú não é muito diferente dos demais conselhos do Estado do Maranhão. Uma das entrevistadas relatou que: "Nós temos 3 câmaras técnicas: câmara de educação do ensino fundamental, que é de educação básica; nós temos a de legislação e normas e a câmara técnica de jovens e adultos. São 3 câmaras internas”. A comissão de avaliação se dá anualmente.

Nós temos dentro do conselho um relatório anual que deverá ser feito pelo relator do conselho, um profissional que é indicado pela Secretaria Municipal de Educação, e que fará, ao término do ano letivo, um relatório e encaminha para as instâncias ligadas ao conselho. Também remete a UNCME, que exige anualmente o relatório para saber do funcionamento. Caso o Conselho Estadual de Educação solicite, deverá ser encaminhado esse relatório. E à própria Secretaria Municipal de Educação, que, enquanto órgão do Sistema Municipal de Educação, e, portanto, paritário, dentro desse processo, exige saber do andamento do conselho.

Quanto aos objetivos do Conselho, uma entrevistada coloca que:

O Conselho tem atingido parcialmente seus objetivos porque quando é a resolução de pendências dentro do aspecto tecnicista como, por exemplo, pendências na vida escolar de alunos, essa lacuna tem sido preenchida, mas quando o objetivo é acompanhamento das políticas públicas no que tange à elaboração, participação, previsão, 
acompanhamento e fiscalização, deixa a desejar. O conselho tem um caráter muito amplo, ele é mobilizador, mobiliza a sociedade civil e organizada para as demandas educacionais, ele é propositivo, propõe, mas sinceramente tenho visto poucas proposições do Conselho, não porque o presidente ou os membros não queiram, mas porque nós ainda temos dificuldade no que diz respeito á garantia da participação nestes processos.

Acrescentou ainda que:

O município de Grajaú tem uma história de desenvoltura educacional que eu vejo como sendo uma das cidades do entorno com uma desenvoltura favorável dentro dos processos educacionais, mas mesmo assim nós não conseguimos acompanhar os níveis de desenvolvimento da educação básica dentro do município por conta de questões burocráticas e de questões que dizem respeito à autonomia do conselho por conta de questões relacionadas à própria burocracia entre instâncias. E isso causa um prejuízo para a educação porque o conselho deveria atuar dentro desse aspecto de acompanhamento das políticas que estão sendo implementadas na educação do município.

Questionada sobre o que deve ser feito para melhorar a atuação do Conselho, um dos entrevistados respondeu que:

A primeira coisa que nós precisamos é garantir a autonomia do conselho. Não tem como um conselho funcionar verdadeiramente se ele não for autônomo. Como exemplo disso, nós temos aqui uma previsão orçamentária destinada à manutenção do conselho, mas essa receita não chega ao domínio da presidência para a sua aplicabilidade, a menos que haja um plano diretivo encaminhando a Câmara Municipal de Vereadores para que seja feita a aprovação disto a fim de que o conselho passe a receber esses valores, essa receita de manutenção e conservação do conselho.

Pontuando de forma mais significativa, a entrevistada informa que:

Isso termina constituindo um empecilho porque se o município tem x números de escolas e o conselho não tem um veículo para deslocamento de uma comissão para averiguar in loco as condições de funcionamento das escolas em questão, nós já temos aí um problema, um bloqueio. Daí, o que precisa ser feito? A Secretaria Municipal de Educação nos fornece um veículo para que façamos isso, mas nós temos toda uma burocracia, temos que encaminhar um ofício para o secretário de educação, que só tem um ou dois veículos para o próprio trabalho da Secretaria, o que inviabiliza o processo. Então, uma dessas instâncias vai ficar bloqueada e na maior parte das vezes é o Conselho, porque as demandas da Secretaria Municipal de Educação, órgão do sistema, paritário ao CME, são emergentes e as do Conselho são urgentes. Ou seja, as de emergência serão as primeiras a serem atendidas. Logo, o Conselho não vai atingir todos os seus objetivos, apesar de planejar, apesar de fazer plano anual, de prever ações, de correr atrás, de previsibilidade, etc e tal, mas não vai conseguir atender as suas demandas internas.

Corroborando de pensamento semelhante, outra entrevistada evidenciou que:

O que eu acrescento de informação acerca do Conselho é que, em Grajaú, nós temos aí uma década e meia de criação do Conselho. E o Conselho já contribuiu muito para o sistema municipal de educação. Considerando que o Conselho Estadual de Educação antes era o responsável pelo reconhecimento, por exemplo, das escolas que funcionam no município de Grajaú. Então, esse Conselho é realmente útil para a sociedade local, mas ele precisa evoluir no que tange à construção de sua autonomia. Sem autonomia, conselho nenhum vai funcionar na sua totalidade. Sem autonomia, nenhum conselho vai atingir sua plenitude. O objeto de atuação do Conselho não é apenas técnico. Volto a dizer, é antes político, o caráter do Conselho é plural. Então, nós precisamos acompanhar as políticas públicas de educação no município. Acompanhar as agendas de educação no Estado. E estar atentos as deliberações no País no que tange à educação, mas, para isso, precisamos de autonomia. Se não tivermos autonomia, se não tivermos apoio, dificilmente vamos conseguir fazer alguma coisa. Para tanto, nós precisamos de um conselho que seja atuante e atuação de um conselho está diretamente relacionada à sua autonomia enquanto instituição do sistema municipal de ensino. E a instituição que compõe o sistema municipal de ensino responsável pela legalização dos estabelecimentos escolares, por resolver pendências de vida escolar dos alunos, a instância responsável por promover diálogos com a comunidade civil local, a instituição responsável por fazer a fiscalização do sistema municipal de ensino, deliberar proposições para a educação à luz do município é uma instituição que não tem na sua composição, por exemplo, a presença de um técnico. Como é que um conselho que não tem um técnico educacional vai conseguir institucionalizar o seu plano, visto que toda e qualquer empresa vai precisar de um apoio jurídico, de um apoio contábil. O conselho não é diferente disso. Nós precisamos ter pessoas que nos deem suporte. Sem o suporte necessário, previsto em lei, nós não vamos conseguir fazer isso. Por isso, para que o conselho atue plenamente, ele precisa estar devidamente amparado com os recursos e o rigor da lei, sem as quais não tem como torná-lo eficiente na sua amplitude, na sua totalidade. Não porque o presidente não queira, não porque o secretário municipal de educação não queira, não porque o conselheiro seja negligente, isso é um conjunto de fatores que 
precisam ser vistos para que o conselho, de fato, venha a funcionar como uma instância verdadeiramente que compõe o sistema municipal de ensino.

Questionada sobre a divisão entre o Estado e a Sociedade Civil, a mesma relatou que:

Eu acredito que pelo que eu tenho conhecimento, a sociedade civil é bem minoritária no sentido de duas ou três classes somente. Estou me lembrando aqui das escolas particulares, dos representantes do comércio e não sei se os pais seriam dessa classificação, mas nós temos os pais de vários segmentos escolares participando também.

No que diz respeito à escolha do presidente, a entrevistada respondeu:

Que eu acompanho, talvez por conta da minha chegada na educação, eu posso falar dessa época, porque antes a gente se reportava à Barra do Corda, mas agora, de um certo tempo para cá, de duas presidências, cada qual com reeleição. Então significa que eu me lembro de quatro mandatos, basicamente, sendo este talvez o quinto, do qual eu faço parte

Acrescentou ainda que:

Na eleição da qual eu fiz parte, não sei te dizer se chegou a conclusão dessa pessoa ser a presidente do Conselho porque quando a gente chega lá, digamos que já esteja mais ou menos andado essa parte, então a gente já tem basicamente um roteiro. As pessoas estão ali convidadas e no caso essa senhora já se manifestou, que também é da área da Educação com esse desejo de ser a presidente. Inclusive foi quem atuou a dois mandatos atrás, ela já havia sido presidente do Conselho em data anterior. E agora se reelegeu. Mas, como se chega a esse nome, devido eu participar apenas dessa outra reunião, eu não sei como isso é feito. Sobre a questão das reuniões, a gente tem um grupo de whatsapp onde a gente recebe as informações, mas se é caso de reunião mesmo, isso vem através de ofício. É oficiado e aí se há quórum para a reunião ser feita, ela nos passa a pauta da reunião, a documentação necessária para ser examinada. Às vezes, se é uma coisa mais rápida ou se a gente precisa de tempo aí é marcada outra reunião, senão já resume logo ali. Depende muito do assunto a ser tratado.

No que diz respeito às pautas das reuniões, a entrevistada respondeu que:

Eu acredito que elas obedeçam a uma demanda porque é o que a gente percebe. Pelo menos nas que eu já participei. A demanda vai surgindo e elas vão sendo montadas. Às vezes, nós temos uma pauta mais extensa, outras vezes uma menor, dependendo mesmo da necessidade do momento.

Quanto às discussões no Conselho, ela relatou que:

Quanto às questões dos termos, eu acho que isso é uma dificuldade até mesmo do paciente e do médico, a gente tem de um lado uma pessoa que domina toda essa nomenclatura e do outro uma pessoa que é leiga, mas eu não acredito que isso se aplique a essa questão aqui, devido nós termos uma pessoa geralmente que trabalha mesmo com a educação. Até mesmo os pais que não são do âmbito educacional, eles têm uma afinidade muito grande porque quando um pai chega a participar do Conselho é porque, de fato, ele se destacou na comunidade escolar. Então, ele é uma pessoa inteirada. A gente não tem muito essa dificuldade em relação aos termos técnicos.

Segundo ela:

Quanto à questão da abrangência da discussão, aí já é outra questão porque a gente sabe também que às vezes a vontade é muita de fazer, mas a impossibilidade também acaba acontecendo. Eu me lembro que no primeiro momento, o Conselho funcionava em uma sala muito inadequada. Depois o município foi lá, estruturou, hoje está mais adequada. Então, assim, entre o discurso e a efetivação dessa realidade é claro que existe uma distância, nem sempre por falta de vontade. A vontade é grande, é tanto que as discussões geralmente são amplas, bem colocadas. Cada setor colocando sua opinião, mas o problema, o gargalo da situação, é a efetivação de tudo isso. É aí que mora o problema.

No que diz respeito à relação da população com o Conselho, a entrevistada disse que:

Olha, essa parte eu desconheço! Eu posso falar um pouco do que eu vi no momento passado, da outra equipe que trabalhou. Acredito que isso obedeça a uma certa demanda. A gente estava na época da formação da BNCC e o conselho foi bastante atuante nessa parte. Visitando todos os setores da sociedade, houve reuniões. Eu acho que foi o momento do Conselho muito presente em todas as camadas sociais porque houve reunião com os indígenas, com as 
escolas particulares, com os quilombolas. Nesse momento, o Conselho se agigantou no município por conta também da demanda existente. Então, passou isso aí, a gente tem agora um outro grupo e uma demanda diferenciada. Agora a gente já tá vivendo um outro momento. E agora nesse momento, eu não estou, sinceramente, a par dessa interação. A gente sabe que o Conselho é muito presente no município, tem um funcionamento próprio, tem um prédio próprio. É muito fácil você localizar o Conselho, mas eu não tenho conhecimento desse veículo.

Sobre o diálogo do Conselho de Educação com outros conselhos ou outras instâncias de organização popular, a entrevistada relatou que:

Eu acredito que sim, mas vou ficar na área do acredito porque nas nossas reuniões, nós temos basicamente o Conselho de Educação. Então, essa ligação, essa conversa, essa estruturação, com certeza é feita em outras ocasiões no município, nas quais nem sempre eu estive presente.

Quanto aos conselheiros, a mesma disse que:

Posso dizer que sim, ressalvando a questão da dificuldade em nível de País de colocar uma coisa em andamento. Posso te dizer que existe uma distância entre o que se conversa e o que de fato é possível fazer. Eu não digo que o Conselho é ausente e que não saiba da sua demanda e que não esteja pronto para discutir sobre ela. Eu digo, por exemplo, que se faltar papel, que é algo cedido pela Prefeitura, impressoras, internet. Toda essa estrutura é fornecida pela Prefeitura. Então se tem, uma coisa vai ser viável, se não tem, nós podemos até ter discutido, mas vai dificultar a implementação desta situação. Quero te dizer, com isso, que não depende apenas do Conselho. A gente precisa, realmente, de mais coisas.

Acrescentou ainda que:

Há uma verba destinada a esse funcionamento. A questão é: Ela chega? Ela é utilizada para isso, de fato? Então, assim, nem sempre o que não está acontecendo é falta de vontade ou falta de articulação. Às vezes eu reúno, eu converso, eu discuto, eu articulo, eu traço um plano, mas a logística do plano não depende, necessariamente, do Conselho.

Quanto ao atingimento dos objetivos, a entrevistada acredita que:

Eu acho que nós esbarramos, exatamente, nessa parte estrutural. E não por falta de previsão de gastos, mas porque existe realmente a dificuldade dessa verba chegar ao seu destino. A gente sabe que o Conselho precisa muito visitar, saber como a escola está acontecendo. E não só na cidade, onde cada conselheiro teria seu próprio veículo, mas, às vezes, em uma região, por exemplo, lá nos quilombolas, será que o plano que a gente traçou tá acontecendo? Seria necessário ir, mas aí já é uma situação onde eu preciso daquele recurso que tá lá. Então, eu acho que o Conselho depende muito dessa parte logística, que é uma parte enfraquecida.

Para melhorar a atuação do Conselho, ela diz precisar de muita coisa.

Eu acho que pelo simples fato desses recursos serem geridos por cada setor, já faria uma grande diferença porque o recurso é do Conselho, mas aí quem gere é a Prefeitura. Não fica complicado? Fica muito difícil de tudo isso acontecer. Se é o Conselho que gere, então porque não há efetivação de tudo aquilo que é colocado, de tudo aquilo que é pensado. Essa questão do recurso precisava ser mais adequada, mais organizada nesse sentido.

No apanhado geral das informações pontuadas pelos entrevistados e pelas respostas dos questionários dar-se uma noção de que há inúmeros gargalos para a participação deliberativa da sociedade. Mas o que fica evidente é que a busca por participar efetivamente do processo decisório não é realizado de forma significativa no Conselho Municipal de Educação do município de Grajaú.

\section{Considerações Finais}

O presente trabalho foi proposto com o intuito de avaliar a concepção da gestão social e da cidadania deliberativa na avaliação do controle social do Conselho Municipal de Educação do município de Grajaú-MA. Nesse contexto, os relatos dos entrevistados demonstram que a cidadania deliberativa se dá de forma moderada, precisando de um maior envolvimento dos 
agentes envolvidos.

Dentre os critérios pesquisados, o referido conselho ainda apresenta dificuldade no estabelecimento de parcerias, o que ocasiona a pouca participação de segmentos diferentes como apoio ás diferentes demandas do conselho.

No que tange a abertura à participação popular é importante pontuar que os canais de comunicação com a comunidade ainda se apresentam como insuficientes, para maior vínculo entre sociedade e o mecanismo de controle social.

Diante dos resultados obtidos na pesquisa de campo, foi possível observar que a concepção da gestão social e da cidadania deliberativa na avaliação do controle social do Conselho Municipal de Grajaú ainda está caminhando para uma maior participação dos conselheiros e efetivação dos objetivos propostos. Em alguns casos foi possível identificar que há um esforço dos conselheiros para manter o mínimo de ações, denotando as dificuldades a qual vivenciam no dia a dia.

Nesse apanhado é notório que a população ainda não participa de forma ativamente das discussões levantadas (seja por desconhecimento ou desinteresse) pelo referido órgão, tendo em vista que ainda é um ponto ser desenvolvido de forma mais eficaz, a ampla propagação de suas ações perante a comunidade. Um dos pontos apontados pelos entrevistados, frisa as diversas dificuldades estruturais e financeira existentes no CME, devido a falta de autonomia para gerir seu funcionamento, pois de um modo geral dependem da Secretaria Municipal de Educação.

Dessa forma, conclui-se que a pesquisa obteve resultados pertinentes, a qual o CME é pontuado com um conjunto de ações moderadas, que podem ser melhoradas a partir de objetivos reais mais pertinentes. A partir do exposto é imprescindível estimar que este trabalho abra inúmeras possibilidades de novos estudos, para que se prossiga a identificação das ações realizadas pelos mecanismos de controle social, em razão de sua extrema relevância para a sociedade.

\section{Referências}

Allebrandt, S. L., \& Tenório, F.G. (2018). Controle Social de Territórios: teoria e prática. Unijuí, v.2.

Bello. S. E. L. (2008). Trabalhos de conclusão de curso nas licenciaturas: a possibilidade de uma experiência na constituição docente. Anais Nacional de Didática e Prática de Ensino/ENDIPE.

Constituição da República Federativa do Brasil de 1988. (2019). Constituição da República Federativa do Brasil: texto constitucional promulgado em 5 de outubro de 1988. http//www.planato.gov.br/ccivil_03/constituição/principal.htm.

Cançado, A. C. Fundamentos teóricos da gestão social. (2011). Tese (Doutorado em Administração) - Universidade Federal de Lavras, Lavras.

Cançado, A. C. (2013). Gestão social: um debate para a construção do campo. NAU Social, 4(6), 191-209.

Cançado, A. C., Pereira, J. R., \& Tenório, F. G. (2013). Gestão Social: epistemologia de um paradigma. CRV.

Comerlatto, D., Matiello, A., Colliselli, L., Renk, E. C., \& Kleba, M. E. (2007). Gestão de políticas públicas e intersetorialidade: diálogo e construções essenciais para os conselhos municipais. Revista Katálysis, 10(2), 265-271.

França, G. C., F'. (2008). Definindo gestão social. En J. T. Silva Jr., R. T. Mâsih, A. C. Cançado, \& P. Schommer. Gestão Social: Práticas em debate, teorias em construção. (Vol. 1). Fortaleza.

Fuks, M.; Perissinotto, R. M.; \& Souza, N. R. (orgs.). (2004). Democracia e participação: os conselhos gestores do Paraná. UFPR.

Gil, A. C. (2011). Métodos e técnicas de pesquisa social. Atlas.

Lei Municipal Nº06/2005 (2005). Dispõe sobre o Conselho Municipal de educação.

Emenda 002 de 29 de novembro de 2016. (2016). Aditiva do art $4^{\circ}$ da lei 006/2005 de criação CME Conselho Municipal de Educação.

Iizuka, E. S.; Gonçalves-Dias, S. L. F.; \& Aguerre, P. (2011). Gestão social e cidadania deliberativa: a experiência de Ilha Comprida. Cadernos Ebape. BR, $9(3), 748-779$.

Nunes, C. O. (2018). Cidadania e desenvolvimento local: o Conselho Municipal de Saúde de Palmas-TO sob a perspectiva da gestão social. (Dissertação de mestrado). Universidade Federal do Tocantins. Palmas.

Oliveira, R. P.; \& Adrião, T. (2007) Organização do Ensino no Brasil: níveis e modalidades na Constituição Federal e na LDB. Xamã.

Silveira, T. S.; Cançado, A. C.; \& Pinheiro, L. S. (2014). A participação no Conselho Municipal de Saúde de Imperatriz-MA na perspectiva da gestão social e da cidadania deliberativa. AOS, 3(1), 45-60. 
Research, Society and Development, v. 10, n. 6, e41910613440, 2021

(CC BY 4.0) | ISSN 2525-3409 | DOI: http://dx.doi.org/10.33448/rsd-v10i6.13440

Tenório, F. G. (2009). Gestão Social: uma réplica. Revista ADM. Made, 13(2), 1-4.

Tenório, F. G. (Org). (2012). Cidadania e desenvolvimento local: critério de análise. Ed. FGV.

Tenório, F. G. (Org). (2016). Cidadania, territórios e atores sociais. FGV. 